\title{
INTRODUCTION - THE PARIS AGREEMENT ON CLIMATE CHANGE
}

\section{Leonie Reins and Geert van Calster}

On 12 December 2015, the Parties to the United Nations Convention on Climate Change ('UNFCCC') adopted the Paris Agreement ('PA') following several years of failed attempts to reach global agreement. ${ }^{1}$ Upon its adoption, the PA was lauded as a triumph of multilateral climate diplomacy. ${ }^{2}$ The Agreement represents the joined understanding of all nations into a common cause to undertake ambitious efforts to mitigate climate change, as well as to adapt to its effects globally. The PA foresees enhanced support for developing countries so as to assist them in meeting these objectives. ${ }^{3}$ The PA is not divided into chapters or subsections, but is structured in a simple manner with a Preamble, followed by 29 operative articles, which set out the Agreement's scope and definitions, main objectives, and institutional provisions. This Commentary on the PA provides a comprehensive, article-by-article, analysis of this groundbreaking agreement. The commentary brings together 22 eminent scholars in the field of climate change, environmental, and energy law, for a detailed examination of the implementation of the PA.

The broad objective of the Paris Agreement is to 'strengthen the global response to the threat of climate change, in the context of sustainable development and efforts to eradicate poverty'. ${ }^{4}$ It seeks to achieve that objective by (i) holding the increase in global average temperature to well below $2^{\circ} \mathrm{C}$ above pre-industrial levels and to pursue efforts to limit the temperature increase to $1.5^{\circ} \mathrm{C}$ above pre-industrial levels; ${ }^{5}$ (ii) increasing the ability to adapt to adverse impacts of climate change; and (iii) making finance flows consistent with a pathway towards low greenhouse gas emissions ('GHG') and 'climate-resilient development'. ${ }^{6}$ Implementation of the PA will take place to 'reflect equity' and 'the principle of common but differentiated responsibilities and respective capabilities'. ${ }^{7}$ As the commentary of Article 2 notes however, this objective is a 'collective goal, framed in aspirational language, and as such does not impose binding obligations in State Parties, despite suggestions to the contrary'. 8 The question of the bindingness of the Agreement is indeed a topic that is discussed in multiple commentaries to the Agreement's provisions. ${ }^{9}$ It has also already surfaced in national courts in various fashion. ${ }^{10}$

1 For a history of the negotiation process of the Agreement refer to the commentary of Article 2.

2 See also the commentary of Article 7 (07.05).

3 Recitals 3 and 5 of the Preamble, as well as the commentary thereto.

4 See also commentary of Article 2 (02.14).

5 For a discussion on the temperature targets see also the commentaries of Articles 2 (02.15f) and 4 (04.03).

6 Article 2(1).

7 Article 2(2).

8 See commentary of Article 2 (02.18).

9 See, e.g., commentaries of Articles 2, 4, 5, 13 , see also L. Rajamani, 'The 2015 Paris Agreement: Interplay Between Hard, Soft and Non-Obligations' (2016) 28 Journal of Environmental Law 337, 352.

10 See for the UK, $R$ (on the application of Plan B Earth) $v$ Secretary of State for Transport et al [2020] EWCA Civ 214. 
To achieve the aforementioned objectives, Parties are required to undertake and communicate so-called Nationally Determined Contributions ('NDCs'). ${ }^{11}$ In addition, Parties commit themselves to pursue domestic mitigation measures 'with the aim of achieving the objectives' of such NDCs. ${ }^{12}$ The PA sets out a detailed administration mechanism of the NDCs that are to be submitted by the Parties. There are requirements relating to transparency and clarity of those NDCs, as well as an obligation to communicate these NDCs every five years. ${ }^{13}$ The Secretariat of the UNFCCC is responsible for administering the NDCs. ${ }^{14}$ Although the PA does not require States to communicate NDCs, at least 147 Parties representing 86 per cent of GHGs voluntarily communicated their intended NDCs before the Paris Agreement was adopted. ${ }^{15}$ It is however also worth noting that seven of the largest emitters are not on track to meet their commitments. ${ }^{16}$

Through the NDCs, 'the Paris Agreement relies on a "bottom-up approach" whereby each State is to decide the ambit of its contribution'. ${ }^{17}$ The approach of introducing NDCs 'to the global response to climate change denotes a new approach to the principle of common but differentiated responsibilities and respective capacities, which has been a point of deep division between States Parties to the UNFCCC'18 for a significant time. As the commentary on Article 3 notes, essentially, the PA imposes an obligation on the Contracting Parties to adopt adequate measures towards the realization of the mitigation targets contained in their respective NDCs. Importantly, this obligation is limited to the climate change mitigation targets themselves, and does not stipulate any specific mitigation measures that some NDCs mention. As a result of this 'obligation of conduct', the international responsibility of a Party to the PA would not automatically be engaged based on the finding that the target was not achieved. ${ }^{19}$ However, international responsibility could arise as a result of a failure to take adequate steps towards achieving that target, regardless of whether the target was ultimately achieved. ${ }^{20}$

Adaptation to climate change is given, for the first time, equal status to mitigation in the context of the Paris Agreement. ${ }^{21}$ A global goal on adaptation is set in Article 7 of the agreement, whereby the adaptive capacity is enhanced, resilience is strengthened and vulnerability is reduced. ${ }^{22}$ Importantly, however, the goal on adaptation is of an aspirational and political nature. ${ }^{23}$ There is, as such, no legal obligation on Parties to the PA to implement it in their national laws and regulations. ${ }^{24}$ Nevertheless, the good faith principle requires Parties not

11 Article 3.

12 Article 4(2) and the commentary thereto.

13 Article 4(8) and Article 4(9) and the commentary thereto.

14 Article 4(12) and Article 17.

15 See commentary of Article 4 (04.13).

16 See commentary of Article 2 (02.37-02.40).

17 See commentary of Article 4 (04.08).

18 See commentary of Article 2 (02.23).

19 Commentary of Article 4 (04.49 and 4.53).

20 Ibid.

21 See also the commentary of Articles 2 (02.19) and 7.

22 See also the commentary of Article 7 (07.21ff).

23 See also ibid. (07.35 and 07.48f).

24 Ibid. 
to simply disregard the adaptation objective of the PA. ${ }^{25}$ Adaptation should take place whilst taking into account the 'urgent and immediate needs of those developing country Parties that are particularly vulnerable to the adverse effects of climate change'. ${ }^{26}$ Increasingly, developing country Parties are adopting national adaptation plans ('NAPs') through a process whose objective is 'to reduce vulnerability to the impacts of climate change by building adaptive capacity and resilience'. ${ }^{27}$

The reference to sustainable development and efforts to eradicate poverty in Article 2 of the Paris Agreement are tied to technology development and transfer. ${ }^{28}$ The PA urges Parties to 'work together and develop long-term innovation plans and policies in respect of environmentally sound technologies'. ${ }^{29}$ In this context, the Technology Mechanism is 'meant to play a pivotal role in encouraging research, development, and diffusion of clean technologies to address climate change mitigation and adaptation'. ${ }^{30}$ Article 10 of the PA recognizes that technology transfer should be supported 'through financial means, by the Financial Mechanism of the Convention, for collaborative approaches to research and development, and facilitating access to technology, in particular for early stages of the technology cycle, to developing country Parties'. ${ }^{31}$ Article 10(5) specifically highlights the close relationship between innovation, climate action, economic growth and sustainable development. Indeed, it provides that '[a]ccelerating, encouraging and enabling innovation is critical for an effective, long-term global response to climate change and promoting economic growth and sustainable development'. 32

Emphasizing the close link with issues relating to sustainable development, developed country Parties are encouraged to take 'the lead by undertaking economy-wide absolute emission targets'. ${ }^{33}$ Developing countries on the other hand are encouraged to continue their mitigation efforts, and to move over time towards economy-wide emission reduction or limitation targets in the light of different national circumstances. ${ }^{34}$ For these efforts, additional support in the form of financial resources shall be provided by developed countries to developing countries in the recognition that this 'will allow for higher ambitions in their actions'. ${ }^{35}$ Special attention is placed on least developed countries ('LDCs') and small island developing States ('SIDs'), who are only requested to 'prepare and communicate strategies, plans and actions for low GHG emissions development'. ${ }^{36}$ 
Voluntary cooperation between the Parties in implementing their respective NDCs is encouraged to allow for a higher level of ambition, as well as to promote sustainable development and environmental integrity. ${ }^{37}$ Cooperation is also emphasized by the recognition that:

adaptation is a global challenge faced by all with local, subnational, national, regional and international dimensions, and that it is a key component of and makes a contribution to the long-term global response to climate change to protect people, livelihoods and ecosystems, taking into account the urgent and immediate needs of those developing country Parties that are particularly vulnerable to the adverse effects of climate change. ${ }^{38}$

Technology development and transfer, as well as capacity-building efforts are also explicitly mentioned by the PA as means to improve resilience to climate change and to reduce GHG emissions' ${ }^{39}$

Participation in the Paris Agreement is nearly universal, with the Agreement emphasizing that developed country Parties should 'continue taking the lead by undertaking economy-wide absolute emission reduction targets' ${ }^{40}$ Of the Parties to the UNFCCC 175 signed the PA, and presently 188 of the 197 signatories have ratified it. ${ }^{41}$ Importantly, the PA foresees that Regional Economic Integration Organisations ('REIOs') may become party to it, with Article 20(2) providing that '[a]ny regional economic integration organization that becomes a Party to this Agreement without any of its member States being a Party shall be bound by all the obligations under this Agreement'. ${ }^{42}$

Parties to the Paris Agreement for which the agreement has entered into force may withdraw after the expiration of a period of three years from the date of that entry into force. Withdrawals take place a year after the receipt of the notification of withdrawal by the Depositary, i.e., the Secretary-General of the UN. ${ }^{43}$ On 4 November 2019, the United States began the process to withdraw from the Paris Agreement by submitting a formal notification of withdrawal to the United Nations. ${ }^{44}$ The United States' withdrawal took effect on 4 November 2020, a year after the delivery of the notification. ${ }^{45}$ However, on 20 January 2021, the Government of the United States of America deposited its instrument of acceptance of the Agreement under the new Biden Administration. ${ }^{46}$ 